\title{
Ion-Implanted Material Leads the Way for New Generation Prosthetics
}

\section{Artificial Hip Joint Presented to President Reagan}

A new process for improving the wear properties of a titanium-based alloy used in artificial hip and knee joints was described to President Reagan in September at a presidential briefing held at the University of Tennessee. Describing for the President the importance of industry/government/university collaboration, Oak Ridge National Laboratory Director Herman Postma chose the new process as a n example of how such cooperative research work can result in a successful commercial product.

Postma emphasized the potential humanitarian and economic benefits of the new process. Approximately 100,000 total hip joints and 60,000 knees are surgically implanted per year in the United States at an estimated cost of some $\$ 3.2$ billion. Many of these are revisions of previous operations, and, in addition, many patients who need surgery are advised to wait until the they are older because the anticipated lifetimes of devices are too short. Improving the technology of prosthetics cannot only alleviate suffering but can also provide economic benefits by reducing the number of revisions, reducing patient care and rehabilitation, reducing the need for pharmaceuticals, and improving the productivity of the workforce.

In laboratory tests, it has been shown that the process, involving the implantation of nitrogen ions in to the near-surface region of the material, reduces the wear rate of the alloy by a factor up to 10,000. The treatment of the alloy also improves the

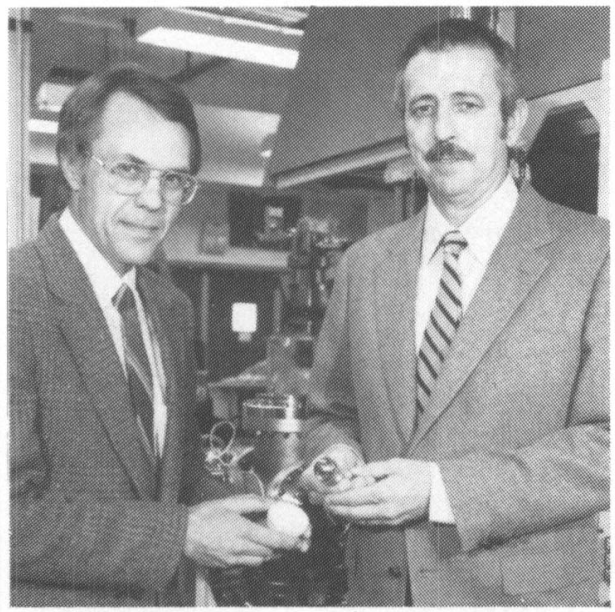

Leaders of the research work, Raymond A. Buchanan (left) and J. M. Williams.

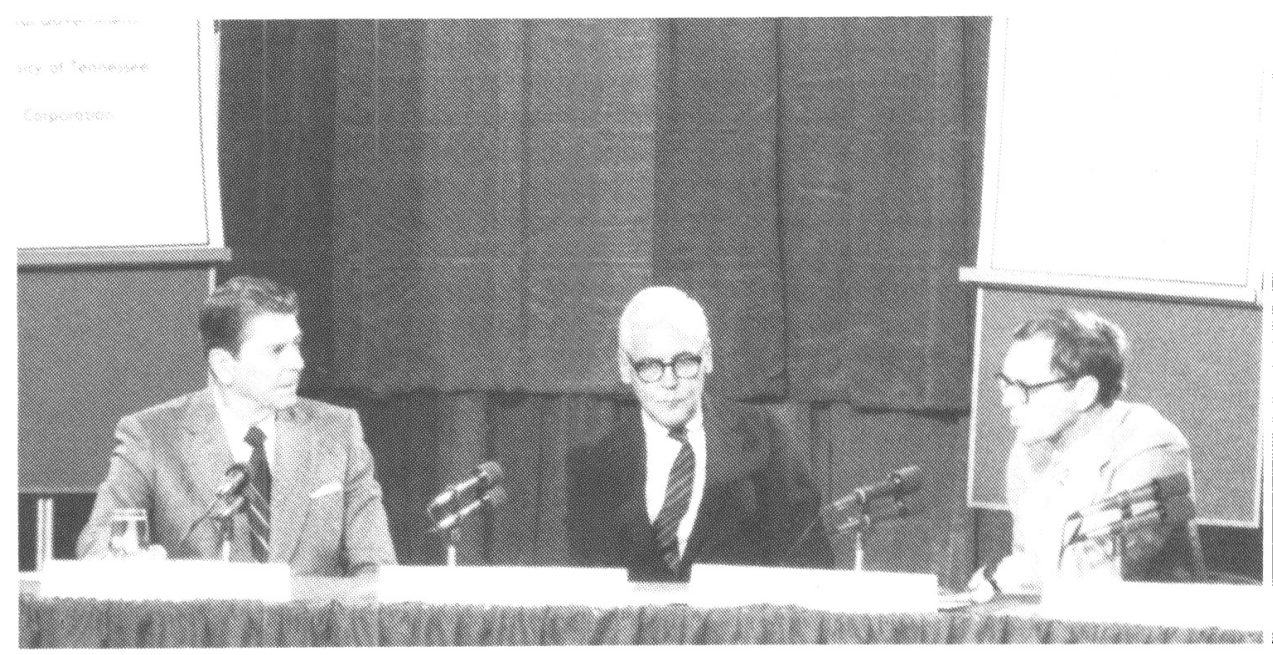

President Reagan listens as Postma (right) discusses research on ion-implanted materials for hip joints. Jack Reese (center), chancellor of the University of Tennessee, looks on.

wear performance of the mating plastic component. These results can contribute directly and indirectly to improved hip and knee joints.

Johnson \& Johnson Products, Inc., Orthopaedics Division and Spire Corporation, two Boston-area firms, are collaborating in marketing products utilizing the new process. Johnson \& Johnson Products, Inc., is a leading national manufacturer of orthopaedic devices and Spire is a high-technology firm whose specialties include ion implantation. Knees are expected to be the first product.

J. M. Williams, scientist in ORNL's Solid State Division, led the collaborative research work with Raymond A. Buchanan of the University of Alabama-Birmingham. Williams is co-chair, with M. F. Nichols and W. Zingg, of MRS's first symposium on Biomedical Materials being held at the 1985 Fall Meeting.

Ti-6A $1-4 \mathrm{~V}$ is a titanium-based alloy originally developed for aerospace applications because of its light weight and high strength properties. Currently, the most important use for ion implantation technology is in the semiconductor industry where it is used to in troduce dopants in to the surface of solidstate electronics. Treatment of orthopaedic devices is expected to be the next important commercial application for the technology. The cost of the treatment is small compared with the substantial surgical and hospitalization costs for a hip or knee operation.

\section{Research Reported at MRS Meetings}

The research in to the use of ion-implanted titanium-based alloy for application in surgical implants was first reported at the 1983 MRS Annual Meeting and is published in lon Implantation and lon Beam Processing of Materials, edited by G. K. Hubler, O.W. Holland, C. R. Clayton, and C. W. White, Volume 27 of the Materials Research Society Symposia Proceedings series. (See "Effect of N-Implantation on the Corrosion-Wear Properties of Surgical Ti-6A1-4V Alloy," by J. M. Williams, G. M. Beardsley, R. A. Buchanan, and R. K. Bacon.)

A panel discussion being conducted at the Biomedical Materials Symposium at the 1985 Fall Meeting will further explore the material for surgical applications. The panel, led by Stephen Gordon of the National Institutes of Health, includes: Raymond Buchanan (University of Alabama-Birmingham), K. W. Greer (Johnson \& Johnson Products, Inc.,), P. Higham (Howmedica, Inc.), J. Parr (Zimmer, Inc.), J. T. Scales (University of London), and D. Mears (University of Pittsburgh). The panel will be conducted Wednesday, December 4, at 3:30 p.m. in the America Ballroom, Westin Hotel

In addition to materials for orthopaedics, other particularly strong aspects of the program include cardiovascular materials and materials for bioelectrodes. The fourday Biomedical Materials Symposium begins on Tuesday, December 3. 


\title{
Fly Ash and Coal Conversion By-Products: Characterization, Utilization and Disposal I
}

\author{
Edited by Gregory J. Mc Carthy \\ and Robert J. Lauf
}

Proceedings of the Symposium held at the 1984 MRS Fall Meeting contains 24 papers which explore analysis and handling of fly ash and consider environmental consequences and potential future uses of the material in industrial or civil engineering applications.

Topics:

- Characterization of fly ash and its reactions in concrete

- Transmitted and reflected visible light microscopy of two bituminous fly ashes

- Scanning electron microscopy and x-ray diffraction analysis of various size fractions of fly ash

- Electrokinetic phenomena and surface characteristics of fly ash particles

- Technical note on the determination of free lime $(\mathrm{CaO})$ in $\mathrm{fly}$ ash

- Characterization of cyrstalline phases in fly ash by microfocus Raman spectroscopy

- Characterization of catalyzed devitrification in quenched fly ash melts

- Retardation effects in the hydration of cement-fly ash pastes

- Reactions products in fly ash concrete

- Autoclave expansion of Portland cement-fly ash pastes

- Effects of fly ash and superplasticizers on the rheology of cement slurries

- Flexural strength and fracture properties of a fly ash blended cement

- Properties and potential uses of the products resulting from the fluidized bed combustion of coal washery wastes

- Utilization of fly ash in roadbed stabilization-some examples of western U.S. experience

- Utilization of fly ash in oil and gas well cementing applications

- Potential resources for coal fly ash

- Characterization of a lignite ash from the METC Gasifier-mineralogy, scanning electron microscopy, and correlations of leaching behavior and mineralogy

- Comparative economics of several alternatives for bulk utilization of fly ash and coal gasification ash

- Disposal of western fly ash in the Northern Great Plains

- Mobility of organic and inorganic constituents from energy and combustion-related wastes under codisposal conditions

- Investigation of leachability of subbituminous fly ash enhanced road based materials

- Technical review of the Energy Authority Coal Waste Artificial Reef Program (C-WARP)

Order Code: 43 MRS Members: $\$ 20 \quad$ U.S. Nonmembers $\$ 30$ Foreign Nonmembers $\$ 36$

Prepayment Required.

Send payment to:

Materials Research Society

9800 McKnight Road, Suite 327

Pittsburgh, PA 15237

telephone (412) 367-3012.

Coming in Early 1986: Fly Ash and Coal Conversion By-Products: Characterization, Utilization and Disposal II 


\section{Visit PLENUM at Booth 923!}

APPLIED SUPERCONDUCTIVITY, METALLURGY, AND PHYSICS OF TITANIUM ALLOYS

\section{Volumes 1 \& 2}

\section{by E. W. Collings}

An encyclopedic treatise on the physical and mechanical metallurgy. low-temperature physics, and superconducting properties of titanium based alloys, particularly $\mathrm{T} i-\mathrm{Nb}$. Collings traces the technical development of hard type-II superconductors from the bench-top superconductive property measurements of the 1960 s to the design, fabrication, and testing of the stable low-loss, high-current composite monolithic and cabled conductors currently in use. Volumes in the International Cryogenics Monograph Series

\section{Volume 1: Fundamentals}

0-306-41690-5/771 pp. + index/ill./1985/\$97.50

\section{Volume 2: Applications}

0-306-41691-3/623 pp. + index/ill./1985/\$87.50

two-volume set: $\$ 160.00$

\section{NONMETALLIC MATERIALS AND COMPOSITES AT LOW TEMPERATURES 3}

\section{edited by Günther Hartwig and David Evans}

This collection of the latest research in the field of nonmetallic materials at low temperatures presents the results of standard and composite materials characterization by practicing engineers and researchers. A volume in the Cryogenics Materials Series.

0-306-42117-8/proceedings/245 pp. + index/ill./1986/\$49.50

\section{FIBER OPTICS}

\section{Technology and Applications}

\section{by Stewart D. Personick}

Dr. Personick, with fifteen years of research and development experience in the field, explains the basic technology and outlines a wide variety of applications including telecommunications point-to-point digital trunks, data links, local area networks, wideband distribution networks, analog links, and sensing systems. Readers will gain a working knowledge of the components and subsystems involved and a clear understanding of the existing and potential implications of fiber optics. A volume in the series Applications of Communications Theory.

0-306-42079-1/270 pp./ill./1985/ $\$ 45.00$

text adoption price on orders of six or more copies: $\$ 29.50$

\section{LIQUID PHASE SINTERING}

\section{by Randall M. German}

Focusing on fundamentals and universal characteristics, this book presents current knowledge on liquid phase sintering. Chapters discuss the basic phenomena, processes, techniques, and technological factors of $\mathrm{li}$ quid phase sintering and survey its diverse commercial and technological applications.

0-306-42215-8/242 pp. + index/ill./1986/\$35.00

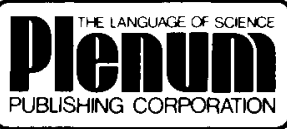

INNOVATIONS IN MATERIALS PROCESSING edited by Gordon Bruggeman and Volker Weiss

Important developments in process modeling and control, processing from the liquid state, processing of particulates, machining technology and surface treatments are discussed in this review of recent innovations in materials processing. Volume 30 in the Sagamore Army Materials

Research Conference Proceedings.

0-306-41839-8/proceedings/534 pp./ill./1985/\$79.50

\section{ADVANCES IN MATERIALS CHARACTERIZATION II}

edited by R. L. Snyder, R. A. Condrate, Sr., and P. F. Johnson

Scientists from a wide range of disciplines have contributed to this presentation of state-of-the-art summaries of established and new methods of materials characterization. A total of 32 papers describe techniques for structural, elemental, phase, surface, interface, and microstructure characterization. Volume 19 in the series Materials Science Research.

0-306-42068-6/proceedings/428 pp./ill./1985/\$69.50

\section{STRENGTH OF INORGANIC GLASS} edited by Charles K. Kurkjian

A compilation of reports on recent advances in fracture mechanics and in the practical and theoretical understanding of the strength of inorganic glasses. Topics discussed include theory, surface chemistry, flaws, fiber technology, and strength and fatigue. Volume 11 in the NATO Conference Series VI: Materials Science.

0-306-42096-1/proceedings/560 pp. + index/ill. $/ 1985 / \$ 89.50$

\section{METAL-CONTAINING POLYMERIC SYSTEMS}

edited by John E. Sheats, Charles E. Carraher, Jr., and Charles U. Pittman, Jr.

Reports rapid developments in the synthesis, characterization, properties, and applications of metal-containing polymers, with an emphasis on conductivity and semiconductivity in materials and catalyses. Discussed are applications of metal-containing polymers in medicine, ion etching, renewable resources, nuclear fusion, solar energy conversion, and cable insulation

0-306-41891-6/proceedings/534 pp./ill./1985/\$79.50

\section{THERMAL CONDUCTIVITY 18}

\section{edited by T. Ashworth and David R. Smith}

This volume brings together a wide range of current research reports on aspects of thermal conductivity and closely related properties. Topics discussed include metastable liquids; solid helium; theory, modeling, and numerical analysis; liquids and gases; salts, oxides, binary compounds; metals and alloys; measurement apparatus and techniques; and insulation, composite, geological, ceramics and glassy materials. 0-306-41918-1/proceedings/784 pp./ill./1985/\$125.00

PLENUM PUBLISHING CORPORATION

233 Spring Street, New York, N.Y. 10013 